\title{
FORMAÇÃO DE PROFESSORES E ENSINO DE DIDÁTICA: PERSPECTIVAS DE NOVAS REFLEXÕES NO AMBIENTE SÓCIO-EDUCACIONAL E POLÍTICO NO INTERIOR DO ESTADO DO AMAZONAS
}

Ademar Vieira dos Santos ${ }^{1}$

Samara Vieira dos Santos ${ }^{2}$

Francisco César Brito Vieira ${ }^{3}$

Doriedson de Oliveira Santos ${ }^{4}$

\section{Resumo}

Este estudo é resultado das experiências como professor da disciplina "Didática" com estudantes de licenciatura do Curso de Biologia e Química da Universidade Federal do Amazonas no Pólo de Saúde e Biotecnologia de Coari na região do Médio Solimões, Amazonas. O curso, tinha como objetivo ensinar a didática dentro de uma concepção transformadora, fazendo com que os estudantes pudessem perceber a didática como uma proposta educativa e política que possibilitasse refletirem sobre suas condições educacionais, políticas e culturais. Como metodologia utilizamos a observação participante que: "Consiste na participação real do pesquisador com a comunidade ou grupo, no qual se encontra inserido e se confunde-se com ele e as práticas cotidianas desses" (MARCONI \& LAKATOS 2009, p. 196) e também de questionários com questões

\footnotetext{
1 É professor mestre formado pela universidade de Lion, Espanha, e atualmente é professor da Universidade Federal do Amazonas - UFAM, no pólo de Saude e Biotecnologia de Coari Rio Solimões. EMAIL <santos.2007@uol.com.br>

${ }^{2}$ Pós-Graduada em Metodologia do Ensino Superior pela Faculdade UNINORTE, Manaus-AM.

${ }^{3}$ Mestrando do Programa de Pós Graduação e Ensino de Ciências na Amazônia, pela Universidade do Estado do Amazonas - UEA.

${ }^{4}$ Pós-Graduado em Metodologia do Ensino Superior, pela Universidade Gama Filho, Manaus-AM.
} 
abertas [...] Assim, para realizar o estudo foi elaborado um questionário com questões abertas são as que permitem ao informante responder livremente, usando linguagem própria, e emitir opiniões. (MARCONI e LAKATOS, 2003, p. 204). Como resultado foi possível perceber que noventa e seis por cento dos estudantes, antes de cursarem a disciplina concebiam a didática como sendo: uma ciência de fazer plano de aula, uma forma de aprender métodos de ensinar, ou não sabiam o que significava. Apenas quatro por cento deles concebiam a didática como uma ciência que trata também das questões sociais e políticas. Ao concluir a disciplina noventa e nove por cento daqueles estudantes, afirmaram que passaram a ter outra concepção sobre didática. Setenta por cento deles conseguiram perceber que a didática trabalhada na escola está relacionada com o contexto histórico cultural da sociedade. Os demais passaram a perceber que a didática possibilita uma melhor compreensão do cotidiano.

Palavras chave: Ensino da Didática e Mudança Socioambiental

\section{Introdução}

Este estudo surgiu da experiência como professor da disciplina "Didática" com estudantes de licenciatura do curso de "Biologia e Química" da Universidade Federal do Amazonas no Pólo de Saude e Biotecnologia de Coari. O texto foi elaborado com base em questionários respondidos pelos estudantes no final da disciplina.

Além dos questionários houve a necessidade de utilização da observação participante que: "Consiste na participação real do pesquisador com a comunidade ou grupo, onde ele se incorpora e é aceito. Fica tão próximo quanto um membro do grupo que está estudando e participa das atividades normais destes" (MARCONI \& LAKATOS 2009, p. 196) 
Os questionários contendo questões abertas foram elaborados a partir de um olhar crítico sobre os conteúdos estudados durante as aulas.

Na primeira questão buscamos saber a concepção de didática que os aprendizes possuíam antes de cursar a disciplina. Na segunda procuramos saber a concepção que passaram a ter ao concluir o curso de didática.

De acordo com o plano de ensino construído, os conteúdos dos textos lidos e debatidos durante as aulas, estudamos a didática dentro de uma concepção transformadora, fazendo com que os aprendizes pudessem superar a concepção conservadora de ensinar, percebendo a didática não apenas como um conjunto de regras e métodos pedagógicos utilizados pelos professores nas suas práticas escolares cotidianas, porém, como uma proposta educativa e política que possibilitasse aos estudantes aprenderem a didática e refletirem sobre suas condições educacionais, políticas e culturais na Região Amazônica.

Com isto tínhamos o propósito de sensibilizar os futuros professores a entender que a didática, ao longo da história do Brasil, de certo forma, sempre foi realizada com a finalidade de reproduzir as estruturas econômicas e políticas nacionais e internacionais que se estabeleceram nas diferentes épocas do capitalismo ocidental. "O ensino de didática foi-se configurando segundo umas características específicas que têm que ser analisadas em função do contexto educacional e político-social em que se situam" (CANDAU 2004, p. 14).

Diante disso, mostramos através das atividades acadêmicas realizadas, que os estudantes como intelectuais orgânicos que são da sociedade, precisam de forma organizada participar dos destinos políticos da sociedade a qual pertencem. "Penso que não há como politizar uma sociedade senão por uma busca convicta de que o melhor modelo político é aquele que garanta a participação nas suas decisões" (GHEDIN 2008, p.282)

Com base nas questões dos questionários respondidos pelos estudantes, após a tabulação dos dados foram construídas as seguintes categorias de análise e reflexão: 
1. A concepção que os estudantes possuíam sobre didática antes de iniciarem a disciplina

Noventa e seis por cento dos estudantes, antes de cursarem a disciplina concebiam a didática como sendo: uma ciência de fazer plano de aula. Uma forma de aprender métodos de ensinar, ou não sabiam o que significava. Apenas quatro por cento deles, concebiam a didática como uma ciência que trata também das questões políticas e sociais.

A compreensão inicialmente apresentada pelos estudantes em relação à didática se deve, de certo modo, às experiências educativas vivenciadas por eles ao longo do ensino básico. A cultura educativa disseminada pelas pedagogias conservadoras, a partir das quais a didática dava mais ênfase à utilização de boas estratégias ou técnica de aplicação e explicação de conteúdos "Toda proposta didática está impregnada, implícita ou explicitamente, de uma concepção do processo de ensino-aprendizagem" (CANDAU 2004, p. 14).

As práticas escolares orientadas com base nas pedagogias conservadoras foram importantes enquanto possibilitaram aos estudantes a aprendizagem de conteúdos universais. Porém, se refletirmos sobre as transformações políticas concretas forjadas com a participação dos sujeitos que saíram das escolas conservadoras veremos que "O ensino tradicional básico falha não tanto por ser disciplinar, mas por não impulsionar e orientar as capacidades cognitivas, inquisitivas e criativas do aluno, e por estar desvinculado dos problemas de seu contexto sociocultural e ambiental" (LEFF 2002, p. 261).

É possível constatar que existe uma grande dívida sócio-educacional, política, cultural e socioambiental com as gerações atuais e futuras, visto que a escola na qual estudaram não Ihes possibilitou a formação de uma mentalidade crítica e política a partir da qual pudessem se engajar como sujeitos na luta pela construção e transformação dos novos cenários políticos da sociedade. "O homem é aquele ser que está sempre 
escolhendo, está sempre se projetando para um comprometimento consigo mesmo, com o mundo e com os outros homens" (PRESTE 2006 p. 152).

O comprometimento político não acontece de forma aleatória, é construído de acordo com o tipo de educação que recebemos na escola que freqüentamos, dos professores com os quais estudamos, com a concepção de homem/mulher que os professores querem para a sociedade a qual pertencem.

Em nosso entendimento, a escola faz parte de um contexto que engloba a sociedade, sua organização, sua estrutura, sua cultura e sua história. Desse modo, o projeto de ensino/aprendizagem está ligado a este contexto e ao modelo de cultura que orienta um modelo de homem/mulher que pretendemos formar para responder os desafios dessa sociedade (GHEDIN, et. al. 2004, p. 42).

Isto de certo modo remete aos professores no interior das escolas do ensino básico ou superior, o compromisso em ressignificar seus planos de ensino e suas práticas escolares, e, por conseguinte a concepção de seus aprendizes sobre a dimensão transformadora da didática. Há assim, uma mobilização aos estudantes da construção de saberes críticos que thes possibilitem refletir, e por conseguinte alterar suas práticas políticas, o engajamento político, a autonomia, e como resultado dessa trajetória a inclusão social. "Não há dúvida alguma de que a superioridade do homem reside no saber. Nele estão guardadas muitas coisas, que os reis com todos os seus tesouros não podem comprar" (HORKEIMER \& ADORNO 1983, p. 89).

Porém, é necessário que se perceba que não se trata de saber apenas reproduzir conteúdos e estratégias didáticas, porém, de conhecimentos, humanos, técnicos, políticos, ambientais e científicos, através dos quais os sujeitos possam estar preparados para atender os desafios epistemológicos, sociológicos, psicológicos e técnicos necessários às exigências da vida social individual e coletiva, e ao mercado de trabalho atual e futuro, e, por conseguinte possam se tornar mais reflexivos, capazes de vislumbrar novas panorâmicas de conquistas sociais e políticas para si e para suas famílias. 
2. A concepção de didática que os estudantes passam a ter após concluir a disciplina e perspectivas de mudanças no ambiente sócio-educacional

Noventa e nove por cento dos estudantes, após a disciplina afirmaram que passaram a ter outra concepção sobre didática.

Setenta por cento deles conseguiram perceber que a didática trabalhada na escola está relacionada com o contexto histórico e cultural da sociedade. Os demais passaram a perceber que a didática possibilita uma melhor compreensão do cotidiano. Através dela é possível até sensibilizar as pessoas na organização e participação coletiva do dia a dia, de modo que possam interagir com os outros, tendo melhor qualidade de vida.

A Didática não trata somente das técnicas e dos métodos práticos que visam à melhoria do ensino. Ela envolve o desenvolvimento humano integral, acompanhando o avanço cognitivo intelectual, considerando igualmente os progressos nos estudos relativos à afetividade, moral idade ou sociabilidade (GHEDIN, et. al. 2004, p. 42 )

As mudanças percebidas na concepção dos estudantes após concluir o curso podem representar um avanço significativo na vida deles e da comunidade onde vivem, visto terem demonstrado que agora estão mais reflexivos, já podem entender com mais clareza a complexidade das políticas públicas dos municípios onde moram, das tendências pedagógicas nas quais se fundamentam as práticas educativas desenvolvidas nas escolas públicas das comunidades interioranas.

A reflexibilidade é a capacidade de voltar sobre si mesmo, sobre as construções sociais, sobre as intenções, representações e estratégias de intervenção. Supõe a possibilidade, ou melhor, a inevitabilidade de utilizar o conhecimento à medida que vai sendo produzido, para enriquecer e modificar não somente a realidade e suas representações, mas também as próprias intenções e o próprio processo de conhecer (LIBÂNEO, 2002, p. 56). 
Percebe-se que os estudantes, a partir das reflexões que agora são capazes de fazer estão mais perceptivos, já demonstram certa incomodação sobre a realidade educacional, econômica e política dos municípios onde residem. "A percepção envolve toda nossa personalidade, nossa história pessoal, nossa afetividade, nossos desejos e paixões, isto é, a percepção é uma maneira fundamental de os seres humanos estarem no mundo" (CHAUI 2003 p. 136)

Essa postura é de fundamental importância na vida desses sujeitos, na medida em que podem utilizar os conhecimentos adquiridos não apenas para refletir sobre suas condições, porém como fundamentos epistemológicos que Ihes possibilitem vislumbrar a construção histórica de suas hegemonias como intelectuais orgânicos que sem dúvida serão no meio amazônico onde atuarão como professores.

O intelectual orgânico das classes subalternas estrutura e cria um terreno para reverter o quadro atual na intenção de construir outras hegemonias. Isto, no entanto, não pode ficar apenas em idéias, pois a luta é bem concreta para a transformação das condições de existência das classes subalternas. Por isso o intelectual é considerado, por Gramsci, como todo aquele que exerce um papel de organização na sociedade (NORONHA 2006, p.176)

O tipo de colonização e exploração econômica pelo qual passaram os povos da Amazônia estabeleceu condições culturais e sociais de extrema alienação e exclusão. Por longos séculos essas comunidades contribuíram no aumento dos índices do número de analfabetos do país. Pertencem a uma das regiões mais ricas em biodiversidades do planeta, porém, ao mesmo tempo em que comporta um grande número de pessoas pobres e excluídas.

Diante dessa panorâmica, percebe-se que há urgente necessidade em formamos professores comprometidos com a luta política, capazes não apenas de serem bons professores de determinadas disciplinas ou conteúdos, porém, bons intelectuais transformadores, desalienadores da sociedade, de modo a sensibilizar as pessoas da localidade ao engajamento político, de tal forma a desconstruir as estruturas hegemônicas que ao longo do período colonial foram construídas nesta região, e que, de certo modo 
ainda fazem parte dos alicerces ideológicos e políticos da classe hegemônica que permanecem no poder. "A atuação na sociedade implica em mexer com as estruturas sociais e políticas, só assim que a construção de um projeto hegemônico, ou contra hegemônico é construído. (NORONHA 2006, p. 176).

Esta situação se apresenta como um desafio aos professores e professoras no interior das comunidades amazonenses, não por serem os únicos responsáveis por mudanças políticas e sociais da região, porém, por serem as pessoas que possuem maior conhecimento crítico sociológico, filosófico e antropológico sobre as questões políticas e sociais locais. "O conhecimento é sempre tradução e reconstrução do mundo exterior e permite um ponto de vista crítico sobre o próprio conhecimento" (MORIN 2001, p. 53).

Os professores precisam estar psicologicamente e politicamente organizados no sentido de traçarem objetivos mútuos, rompendo ao mesmo tempo com o monólogo e resolvendo os seus problemas educacionais, políticos e ambientais de forma dialogal. "Pelo diálogo permanente e crítico, professor e aluno fazem pesquisa, cujo objeto é a cotidianidade. Frutos da reflexão sobre a ação, as ideias então formadas não são aceitas como modelos, mas entendidas como parte de um processo de recriação permanente" (SAVIANI 1998, p. 41).

Isto exige que professores e aprendizes desenvolvam o espírito da dúvida e da crítica, não no sentido de desacreditar e sair formulando críticas aleatórias a todo o conhecimento já elaborado, mas com o intuito de adquirir o hábito e as habilidades para a prática da descoberta científica, da pesquisa, sem a qual não se pode trabalhar de forma interdisciplinar, de modo a dar ressignificação aos conhecimentos já elaborados e modificar de forma sustentável o cotidiano ambiental que lhes envolve.

O processo dialético de conhecimento da realidade, o que importa fundamentalmente não é a crítica pela crítica, mais a crítica e o conhecimento crítico para uma prática que altere e transforme a realidade anterior no plano do conhecimento (FRIGOTO, 1993, p. 81). 
Isto de certo modo proporcionará aos aprendizes uma concepção transformadora de ensinar, de modo que possam, a partir de um plano educacional interdisciplinar, fazer com que os homens e as mulheres amazonenses possam se perceber como "sujeitos participes" de uma totalidade, "na sua essência" "o homem todo" "um ser no mundo".

Esse cenário não pode ser ensinado, ele terá de ser construído a partir da convivência que os atores sociais se dispõem a viver no dia-a-dia na imensidão dos assentamentos rurais, das vilas, pequenas e grandes cidades no interior do Amazonas.

\section{Considerações finais}

Diante dos objetivos inicialmente construídos no plano da disciplina, das aulas desenvolvidas em sala, das manifestações dos estudantes durante a apresentação das atividades, dos questionários respondidos por eles no final da disciplina, verifica-se que os resultados foram bastante proveitosos, que os conteúdos, da forma como foram trabalhados atingiram de certo modo a alma da maioria dos estudantes, como dizia o Educador Paulo Freire. Não aprenderam simplesmente didática pela didática.

Isto é de extrema relevância no processo de desenvolvimento político e social dos estudantes amazonenses, que logo mais estarão se tornando professores em alguma cidade ou comunidade do grande vale amazônico. Visto a possibilidade que terão de sensibilizar e, por conseguinte vislumbrar juntamente com as suas comunidades novas perspectivas de mudanças estruturais como sujeitos protagonistas do meio onde estarão inseridos.

Portanto, acreditamos que o conhecimento de didática, da forma como foi aprendido pelos estudantes do curso de Química e Biologia foi significativa na vida acadêmica daqueles aprendizes que terão de construir sua cidadania, de suas famílias e comunidades, sensibilizando as autoridades governamentais para a criação de políticas públicas concretas que viabilizem a promoção de condições de vida mais humana e sustentável no meio onde vivem. 


\section{REFERÊNCIAS}

CANDAU. Vera Maria. A Didática em questão. Petrópolis: Vozes 2004.

CHAUI, Marilena. Convite a Filosofia. São Paulo: Editora Ática 2003.

FRIGOTO, Gaudêncio. O enfoque da dialética materialista histórica na pesquisa educacional. In: FAZENDA Ivanir (Org.). Metodologia da pesquisa educacional. São Paulo: Cortez, 1991.

GHEDIN, Evandro. Reflexão sobre Educação e Despolitização. In: GHEDIN. Evandro. $O$ vôo da Borboleta. Interfaces entre educação do Campo e Educação de Jovens e Adultos. Manaus: UEA Valer 2008.

Amazonas: 2003 .

et. al. Manual Didática I. Manaus: Universidade do Estado do

LAURIA, Evelyn. A filosofia da educação e a formação do intelectual orgânico em Gramsci In GHEDIN, Evandro (Org.). Temas em Filosofia da Educação. Manaus AM: Valer, 2006: 171-176.

LEFF, Enrique. Saber Ambiental. Sustentabilidade, Racionalidade, Complexidade e Poder. Petrópolis: Vozes 2002.

LIBÂNEO, José. Reflexibilidade e formação de professores: outra oscilação do pensamento pedagógico brasileiro. In PIMENTA e GHEDIN (Orgs.). Professor Reflexivo no Brasil: gênese e crítica de um conceito. São Paulo: Cortez, 2002, 56.

MORIN, Edgar. Saberes Globais e Saberes Locais. O olhar transdisciplinar. Rio de Janeiro: Garamond 2002.

HORKHEIMER, MAX \& ADORNO, Theodor. Conceito de lluminismo. Os pensadores. São Paulo: Editora Civita 1983.

PRESTE, Lenize. A filosofia da Educação em Sartre. In: GHEDIN, Evandro. Org. Temas em Filosofia da Educação. Manaus: Editora Valer 2006.

SAVIANI, Nereide. Saber escolar, currículo e didática - Problemas da unidade conteúdo/método no processo pedagógico. São Paulo: Autores Associados, 1998. 